\title{
IGF-1 may predict the severity and outcome of patients with sepsis and be associated with microRNA-1 level changes
}

\author{
LIANG XU ${ }^{1}$, WEIJUN ZHANG ${ }^{2}$, RENHUA SUN ${ }^{1}$, JINGQUAN LIU $^{1}$, JUN HONG $^{1}$, \\ QIAN LI ${ }^{1}$, BANGCHUAN HU $^{1}$ and FANGXIAO GONG ${ }^{1}$ \\ ${ }^{1}$ Department of Intensive Care Unit, Zhejiang Provincial People's Hospital, Hangzhou, Zhejiang 310014; ${ }^{2}$ Department \\ of Neurology, Zhejiang Provincial Hospital of Traditional Chinese Medicine, Hangzhou, Zhejiang 310006, P.R. China
}

Received June 3, 2015; Accepted February 23, 2017

DOI: $10.3892 / \mathrm{etm} .2017 .4553$

\begin{abstract}
IGF-1 functions as an anti-oxidative stress molecule and some critical patients with sepsis have a lower level of serum IGF-1. However, the association between IGF-1 and the severity or prognosis of sepsis remains unclear. This study aimed to elucidate the relationship between serum IGF-1 levels and the severity and prognosis of sepsis, and the possible mechanism was analyzed. Clinical characteristics of patients with sepsis were recorded and analyzed. Serum IGF-1 levels and micro (mi)RNA-1 levels were tested using radioimmunoassay and reverse transcription-quantitative polymerase chain reaction (RT-qPCR) analysis, respectively. The A549 cell line and $\mathrm{HKC}$ cell line were cultured in vitro and exposed to $\mathrm{H}_{2} \mathrm{O}_{2}$ with or without IGF-1 treatment. Cell death was detected by analyzing cell death markers via ELISA kits, and miRNA-1 levels were detected after $\mathrm{H}_{2} \mathrm{O}_{2}$ exposure using RT-qPCR analysis. miRNA-1 in cells was upregulated by transfection and IGF-1 mRNA was detected to determine its relationship with miRNA-1. Once again, cell ELISA kits were used to analyze cell death markers after transfection. Serum IGF-1 levels were reduced in patients with sepsis, whereas miRNA-1 levels were higher $(\mathrm{P}<0.05$ vs. healthy control). Patients in the septic shock subgroup or dead patients had the lowest IGF-1 levels and the highest miRNA-1 levels ( $\mathrm{P}<0.05$ vs. sepsis and severe sepsis). IGF-1 levels were inversely proportional to the miRNA-1 level. In vitro, IGF-1 reduced the cell death caused by $\mathrm{H}_{2} \mathrm{O}_{2}$. miRNA-1 transfection effectively increased the sensitivity of cells to $\mathrm{H}_{2} \mathrm{O}_{2}$ damage by reducing the expression of IGF-1, which was able to prevent cells from injury caused by $\mathrm{H}_{2} \mathrm{O}_{2}$. The transfection of negative control miRNA did not influence the level of IGF-1 miRNA and the sensitivity to $\mathrm{H}_{2} \mathrm{O}_{2}$ damage. In conclusion, low IGF-1 levels in patients with sepsis may
\end{abstract}

Correspondence to: Dr Weijun Zhang, Department of Neurology, Zhejiang Provincial Hospital of Traditional Chinese Medicine, 54 Youdian Road, Hangzhou, Zhejiang 310006, P.R. China E-mail: zhangweijunzjh@163.com

Key words: sepsis, insulin-like growth factor-1, microRNA-1, outcome predict increased severity of the condition and poor prognosis. The possible mechanism is that the excessive miRNA-1 levels reduce IGF-1 levels, resulting in insufficient anti-oxidative action by IGF-1 which increases the injury caused by oxidative stress in patients with sepsis.

\section{Introduction}

Sepsis is a systemic inflammatory response syndrome caused by infection. Septic shock and multiple organ dysfunction syndrome (MODS) often occur in patients with sepsis $(1,2)$. Despite decades of research, the mortality rates of patients with sepsis remain high and sepsis is one of the major reasons for deaths of patients in ICU (3). Therefore, it is necessary to diagnose sepsis timely and accurately in order to reasonably evaluate the severity and prognosis of patients with sepsis. In addition to the uncontrolled inflammation reactions, oxidative stress is an important factor in the occurrence and progression of sepsis. In sepsis, the inflammatory response and oxidative stress often interact as both the cause and effect, forming a vicious cycle and eventually resulting in damage to tissue and multiple organs $(4,5)$. Therefore, studies on oxidative stress in patients with sepsis can be beneficial in furthering the understanding of the diagnosis, evaluation and treatment of sepsis. Insulin-like growth factor-1 (IGF-1) functions to maintain cell survival and proliferation and anti-apoptosis mechanisms. Studies have shown that IGF-1 also has anti-inflammation and anti-oxidative effects against stress injuries $(6,7)$. Studies have also demonstrated that IGF-1 is regulated by oxidative stress. Notably it has also been demonstrated that IGF-1 levels in blood samples are reduced in the acute phase for critical patients (8). However, it remains unclear whether IGF-1 has an anti-oxidative stress role in sepsis and the association between IGF-1 and the severity or prognosis of patients with sepsis is also ambiguous.

Micro (mi)RNAs, a type of small non-coding RNAs, are also being increasingly investigated in studies about critical diseases, and bioinformatics studies have shown that IGF-1 may be a target gene of miRNA-1 $(9,10)$. Therefore, this study was not only designed to investigate whether serum IGF-1 levels could predict the severity and prognosis in patients with sepsis, but we also tried to determine the association between IGF-1 and miRNA-1 in patients. $\mathrm{H}_{2} \mathrm{O}_{2}$ has previously been proven to induce oxidative injury in cells $(11,12)$; therefore, 
in vitro we used $\mathrm{H}_{2} \mathrm{O}_{2}$ to simulate oxidative stress in order to reveal the underlying mechanism involved in miRNA-1 and oxidative stress.

\section{Materials and methods}

Patients and study design. A total of 64 patients (age $48.9 \pm 7.3$ years; 35 male, 29 female) with sepsiswere enrolled between June 2012 and July 2014 and were used as the research subjects. The diagnostic criteria for sepsis were in accordance with the definitions provided by the American College of Chest Physicians and the Society of Critical Care Medicine (13). A total of 35 healthy volunteers (age $48.2 \pm 4.9$ years; 25 males, 10 females) who underwent physical examination at the hospital during the same period were included as healthy control subjects. Exclusion criteria were: Aged $<18$ years old; suffering from cancer; pregnancy; patients with severe chronic diseases of the heart, liver, kidney or lung; and patients died within $24 \mathrm{~h}$ of hospitalization. After patients with sepsis were enrolled in the Intensive Care Unit (ICU), their age, sex, medical history, diagnosis and sepsis-related organ failure assessment (SOFA) score were recorded, their vital signs were monitored, and blood gas analysis was performed. Conventional treatment was performed, with a 28-day follow-up period. All patients with sepsis were divided into three subgroups depending on the severity (sepsis, severe sepsis or septic shock). Sepsis complicated by organ dysfunction is referred to as severe sepsis, while sepsis complicated by hypotension refractory to adequate volume resuscitation in the absence of an alternate cause is termed septic shock (14).

All patients were divided into a survival group or death group according to their 28-day survival. This study was approved by Medical Ethics Committee of Zhejiang Provincial People's Hospital and all subjects gave written informed consent.

Detection of IGF-1 levels by radioimmunoassay. Venous blood samples $(3 \mathrm{ml})$ were collected from patients with sepsis within $12 \mathrm{~h}$ after diagnosis and the subjects in the healthy control group. After standing for $4 \mathrm{~h}$ at room temperature, the samples were centrifuged at $2,500 \mathrm{x}$ g for $15 \mathrm{~min}$ at room temperature to separate the serum. Serum IGF-1 content was detected by a radioimmunoassay kit (DSL-10-9400; Diagnostic Systems Laboratories, Inc., Webster, TX, USA) in strict accordance with the manufacturer's protocol using a radioimmunoassay system (M3687; Beijing Midwest Technology Co., Ltd., Beijing, China).

Detection of miRNA-1 levels by reverse transcription-quantitative polymerase chain reaction (RT-qPCR). miRNA was extracted from serum specimens using a MiRcute miRNA Extraction-Separation kit (Beijing Tiangen Biotech Co., Ltd., Beijing, China) according to the manufacturer's instructions. After the purity and concentration was measured, RT of the miRNA to cDNA was performed using a One Step PrimeScript miRNA cDNA synthesis kit (Dalian Takara Co., Ltd., Dalian, China). RT was performed in a T100 Thermal Cycler PCR system (Bio-Rad Laboratories, Inc., Hercules, CA, USA) and the reaction conditions were prepared according to the instructions. The obtained cDNA was amplified by qPCR using SYBR Premix Ex Taq II (Dalian Takara Co.,
Ltd.). qPCR was performed in a Thermal Cyclers Dice real time PCR system (Bio-Rad Laboratories, Inc.). Thermal reaction conditions were in accordance with the manufacturer's instructions: Each $15 \mu \mathrm{l}$ of reaction mixture was incubated for $10 \mathrm{sec}$ at $95^{\circ} \mathrm{C}$ and then amplified for 40 cycles. Each cycle had two steps; $95^{\circ} \mathrm{C}$ for $5 \mathrm{sec}$ and $60^{\circ} \mathrm{C}$ for $30 \mathrm{sec}$. The miRNA-1 upstream primer sequence was $5^{\prime}$-GCGTGGAAT GTAAAGAAGTAT-3'. Data were normalized by cel-miR-39 as reference, its upstream primer sequence was 5'-GGAGGT TAATGCTAATTGTGATAG-3'. Relative expression levels of miRNA-1 were expressed as $2^{-\Delta \Delta \mathrm{Cq}}(15)$.

Cell culture. Human alveolar epithelial cells (A549 cell line) and human embryonic kidney cells (HKC cell line) were purchased from Cell Bank of the Chinese Academy of Sciences (Shanghai, China). All cells were cultured in Dulbecco's modified Eagle medium supplemented with 10\% fetal bovine serum (Gibco; Thermo Fisher Scientific, Inc., Waltham, MA, USA) at $37^{\circ} \mathrm{C}$ in an environment containing $5 \% \mathrm{CO}_{2}$.

Cell exposure to $\mathrm{H}_{2} \mathrm{O}_{2}$ and cell death detection via ELISA. A549 cells and HKC cells were prepared into cell suspensions, planted in 96-well plates at $1 \times 10^{4}$ cells/well, and routinely cultured for $24 \mathrm{~h}$. Cells were exposed to $100 \mu \mathrm{M} \mathrm{H}_{2} \mathrm{O}_{2}$ for $48 \mathrm{~h}$ to simulate oxidative stress. To confirm the protective effect of IGF-1, some cells received treatment with $30 \mathrm{ng} / \mathrm{ml}$ IGF-1 while exposed to $\mathrm{H}_{2} \mathrm{O}_{2}$. The number of DNA fragments of apoptotic cells was detected via a cell death detection ELISA kit (Roche Diagnostics GmbH, Basel, Switzerland) using an ELX808 microplate reader (BioTek Instruments, Inc., Winooski, VT, USA), which reflects the apoptotic conditions of the cells.

Detection of miRNA-1 in cells after $\mathrm{H}_{2} \mathrm{O}_{2}$ exposure. A549 cells and $\mathrm{HKC}$ cells were treated with $100 \mu \mathrm{M} \mathrm{H}_{2} \mathrm{O}_{2}$ and, after $48 \mathrm{~h}$, cells were collected and the miRNA- 1 changes in cells were analyzed by RT-qPCR using the protocol outlined. To normalize the RT-qPCR data, U6 small nuclear RNA was used as a reference, its upstream primer sequence was 5'-CTCGCT TCGGCAGCACA-3'.

miRNA-1 transfection and detection ofIGF-1 mRNA. A549 cells and HKC cells were prepared into cell suspension, and inoculated on 96-well plates at a density of 6,000 cells/well. When the confluency of cells reached $\sim 80 \%$, the miRNA-1 mimics were transfected into cells using a Lipofectamine ${ }^{\circledR} 2000$ transfection kit (Invitrogen; Thermo Fisher Scientific, Inc.). The working concentration of miRNA-1 mimics was $50 \mathrm{nM}$. The unrelated miRNA-1 mimic negative controls were transfected using the same procedure. Cells were cultured continuously for $48 \mathrm{~h}$ and the transfection effect was validated by RT-qPCR. IGF-1 mRNA levels in A549 and HKC cells after transfection were detected by RT-qPCR. Briefly, total RNA in cells was extracted by TRIzol reagent (Invitrogen; Thermo Fisher Scientific, Inc.). Total RNA was reverse transcribed into cDNA using a PrimeScript RT reagent kit (Dalian Takara Co., Ltd., Dalian, China). The RT system was used in accordance with the manufacturer's instructions. The synthesized cDNA was amplified using a SYBR Premix Ex Taq II kit. The following primers were used: IGF-1, upstream 5'-TGCTCTCAACAT CTCCCATC-3' and downstream 5'-GAAGAGATGCGA 
Table I. Baseline data of healthy subjects and patients with sepsis.

\begin{tabular}{|c|c|c|c|c|c|}
\hline & \multirow[b]{2}{*}{$\begin{array}{l}\text { Healthy control } \\
\qquad(\mathrm{n}=35)\end{array}$} & \multicolumn{3}{|c|}{ Sepsis patients $(n=64)$} & \multirow[b]{2}{*}{ P-value } \\
\hline & & $\begin{array}{l}\text { Sepsis subgroup } \\
\qquad(n=15)\end{array}$ & $\begin{array}{l}\text { Server subgroup } \\
\qquad(\mathrm{n}=30)\end{array}$ & $\begin{array}{c}\text { Septic shock } \\
\text { subgroup }(n=19)\end{array}$ & \\
\hline Age (years) & $48.2 \pm 4.9$ & $47.3 \pm 3.6$ & $49.5 \pm 4.2$ & $49.8 \pm 6.1$ & $>0.05$ \\
\hline Sex & & & & & $>0.05$ \\
\hline Male & 25 & 7 & 17 & 11 & \\
\hline Female & 10 & 8 & 13 & 8 & \\
\hline Blood culture & & & & & $>0.05$ \\
\hline Negative & - & 3 & 3 & 2 & \\
\hline $\mathrm{Gram}^{+}$bacteria & - & 2 & 11 & 6 & \\
\hline Gram $^{-}$bacteria & - & 8 & 15 & 9 & \\
\hline Fungi & - & 2 & 1 & 2 & \\
\hline Primary infection site & & & & & $>0.05$ \\
\hline Lower respiratory tract & - & 1 & 3 & 1 & \\
\hline Upper respiratory tract & - & - & 2 & 2 & \\
\hline Urinary tract & - & 1 & 5 & 2 & \\
\hline Abdomen & - & 13 & 20 & 11 & \\
\hline SOFA score (range) & - & $6(3-7)$ & $7(4-9)$ & $10(7-11)$ & $<0.05$ \\
\hline 28-day survival & - & & & & $<0.05$ \\
\hline Yes & - & 10 & 20 & 6 & \\
\hline No & - & 5 & 10 & 13 & \\
\hline
\end{tabular}

GGAGGACA-3'; and GAPDH, upstream 5'-ACCACAGTC CATGCCATCAC-3' and downstream 5'-TCCACCACCCTG TTGCTGTA-3'. The reaction system and program was used in accordance with the manufacturer's instructions. Relative expression of target IGF-1 mRNA was analyzed according to the $2^{-\Delta \Delta} \mathrm{Cq}$ method $\left(\Delta \mathrm{CT}=\mathrm{CT}_{\mathrm{IGF-}-1}-\mathrm{CT}_{\mathrm{GAPDH}}\right)$.

Assay for the effect of miRNA-1 transfection on the apoptosis induced by $\mathrm{H}_{2} \mathrm{O}_{2}$. Transfected A549 cells and HKC cells were treated with $100 \mu \mathrm{M} \mathrm{H}_{2} \mathrm{O}_{2}$, after $48 \mathrm{~h}$. The number of DNA fragments of apoptotic cells was detected by a cell death detection ELISA kit.

Statistical analysis. Data analysis was performed using SPSS 19.0 software (IBM SPSS, Armonk, NY, USA). Measurement data were expressed as the mean \pm standard deviation. For normality data, analysis of variance was performed for comparison between multiple groups, and unpaired- t test was performed to compare between two groups. For the non-normal data, Mann-Whitney non-parametric U-test was performed to compare between two groups. Spearman correlation analysis was performed. The survival analysis adopted Kaplan-Meier curves. $\mathrm{P}<0.05$ was considered to indicate a statistically significant difference.

\section{Results}

Baseline clinical data in patients with sepsis. A total of 35 healthy subjects and 64 patients with sepsis were included in this study (Table I). The healthy control group included
25 males and 10 females, with a mean age of $48.2 \pm 4.9$ years; whereas the sepsis group included 35 males and 29 females, with a mean age of $49.6 \pm 9.6$ years. The patients with sepsis were further divided into subgroups according to the severity of disease, with 15 cases in the sepsis subgroup, 30 cases in the severe sepsis subgroup, and 19 cases in the septic shock subgroups. During 28 days of follow-up, 36 patients survived and 28 succumbed to shock. As shown in Fig. 1, the median SOFA score of patients with septic shock was 10 (7-11), which was significantly higher than that of the other two subgroups (6 and 7; $\mathrm{P}<0.05$ ). The median SOFA score of dead patients was significantly higher than that of the patients who survived follow-up (9 vs. 7; $\mathrm{P}<0.05$ ). There were no significant differences in age, sex and medical history between the healthy control group and the sepsis group. Furthermore, there were no significant differences in the age, sex, medical history, infection site and type of infected bacteria between the sepsis subgroups.

Serum IGF-1 levels correlate with the severity and prognosis of patients with sepsis. As shown in Fig. 2A, median serum IGF-1 levels in patients with sepsis and in healthy controls were $85.28 \mathrm{ng} / \mathrm{ml}(36.24-119.28 \mathrm{ng} / \mathrm{ml})$ and $159.79 \mathrm{ng} / \mathrm{ml}$ (134.02-188.96 ng/ml), respectively, with a significant difference detected $(\mathrm{P}<0.05)$. In addition, with the aggravation of sepsis, IGF-1 levels declined. As compared with the patients in the sepsis and severe sepsis subgroups, patients in the septic shock subgroup exhibited the lowest IGF-1 levels $(\mathrm{P}<0.05$; Fig. 2B). For all patients with sepsis, their IGF-1 levels were inversely proportional to their SOFA scores 

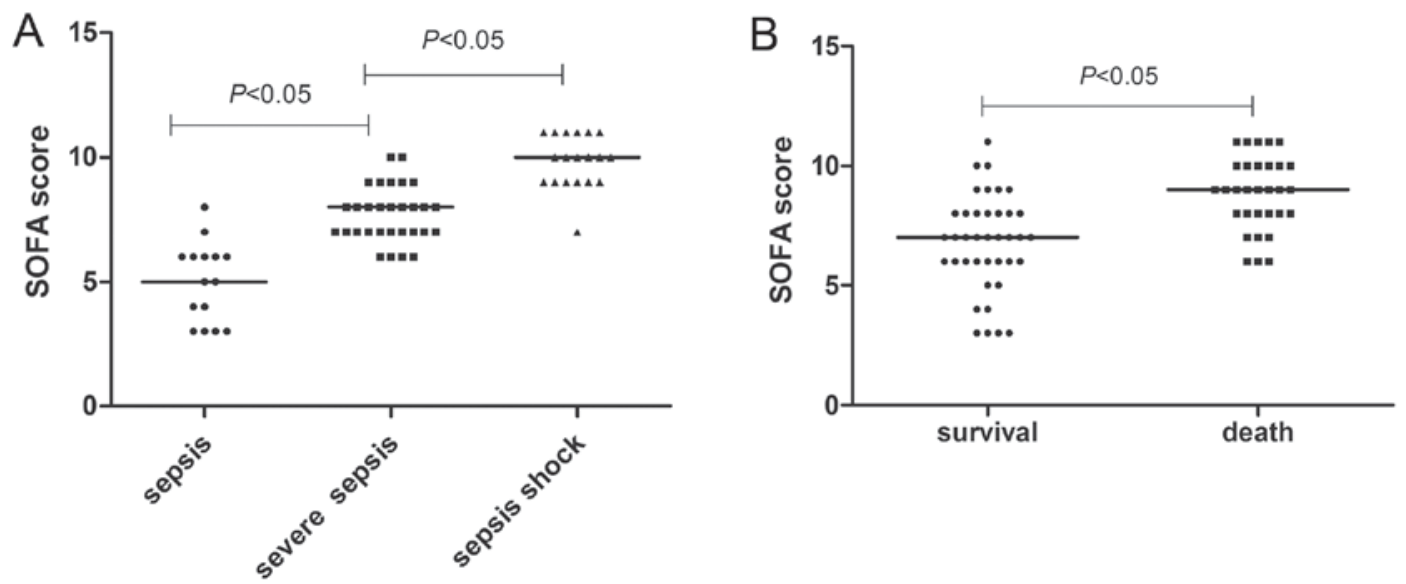

Figure 1. SOFA score in patients with sepsis. (A) SOFA scoring correlated with severity for patients with sepsis. (B) SOFA scores were higher in dead patients. Only significant P-values are shown. SOFA, sepsis-related organ failure assessment.
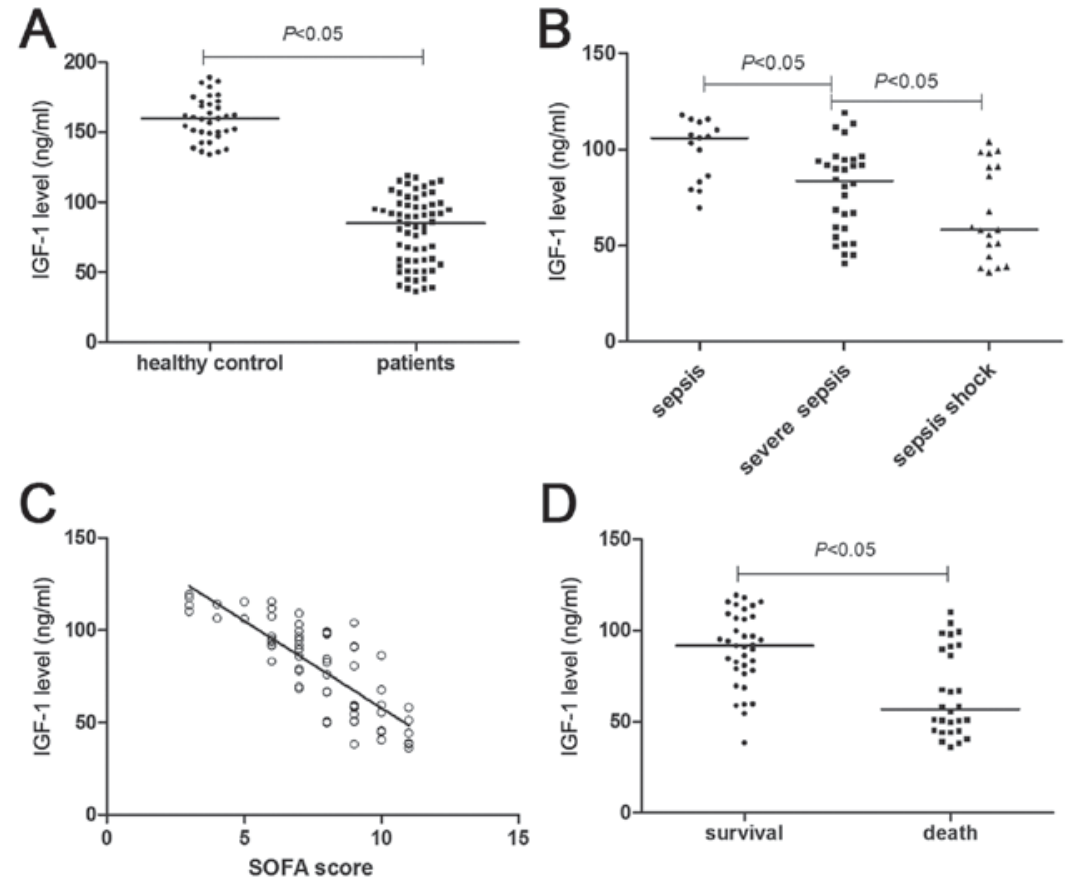

Figure 2. Serum IGF-1 level changes in patients with sepsis. (A) Serum IGF-1 decreased in patients with sepsis compared with the healthy control group. (B) Serum IGF-1 levels were correlated with the severity of illness for patients with sepsis. (C) IGF-1 levels were inversely proportional to SOFA scores in patients with sepsis. (D) IGF-1 levels were lower in patients with sepsis that did not survive the 28-day follow-up period, as compared with the patients that did survive. Only significant P-values are shown. IGF-1, insulin-like growth factor; SOFA, sepsis-related organ failure assessment.

$(r=-0.66$; $\mathrm{P}<0.05$; Fig. $2 \mathrm{C})$. These results suggested that a decline in IGF-1 may predict a more severe condition of sepsis. For the prognosis, the median IGF-1 level of patients in the death group was significantly lower than that of the survival group (91.75 vs. $56.84 \mathrm{ng} / \mathrm{ml}$; $\mathrm{P}<0.05$; Fig. 2D). The area under the receiver operating characteristic curve for predicting the mortality of patients with sepsis using IGF-1 was 0.779 (95\% confidence interval: 0.661-0.897), and the cut-off point was $68.10 \mathrm{ng} / \mathrm{ml}$ (Fig. 3), which was used to divide all patients with sepsis into either low and high IGF-1 level groups. Kaplan-Meier survival analysis showed that the 28-day survival rate of patients in the low IGF-1 level group was significantly lower than in the high IGF-1 level group (21.7 vs. $77.5 \%$; P<0.05; Fig. 4).
Increased serum miRNA-1 levels in patients with sepsis are inversely proportional to serum IGF-1 levels. RT-qPCR results (Fig. 5A) showed that miRNA-1 levels of patients with sepsis significantly increased $(\sim 1.5$-fold) as compared with the healthy controls $(\mathrm{P}<0.05)$. As shown in Fig. 5B and $\mathrm{C}$, with the aggravation of the septic conditions, miRNA-1 levels significantly increased $(\mathrm{P}<0.05)$. Patient miRNA-1 levels were shown to be directly proportional to the SOFA score $(r=0.606 ; \mathrm{P}<0.05)$. In addition, the miRNA-1 levels of the dead patients were higher than that of the patients who survived follow-up $(\mathrm{P}<0.05$; Fig. 5D). Notably, correlation analysis showed that the serum IGF-1 levels of patients were inversely proportional to serum miRNA-1 levels $(r=-0.692$; $\mathrm{P}<0.05$; Fig. 6). 


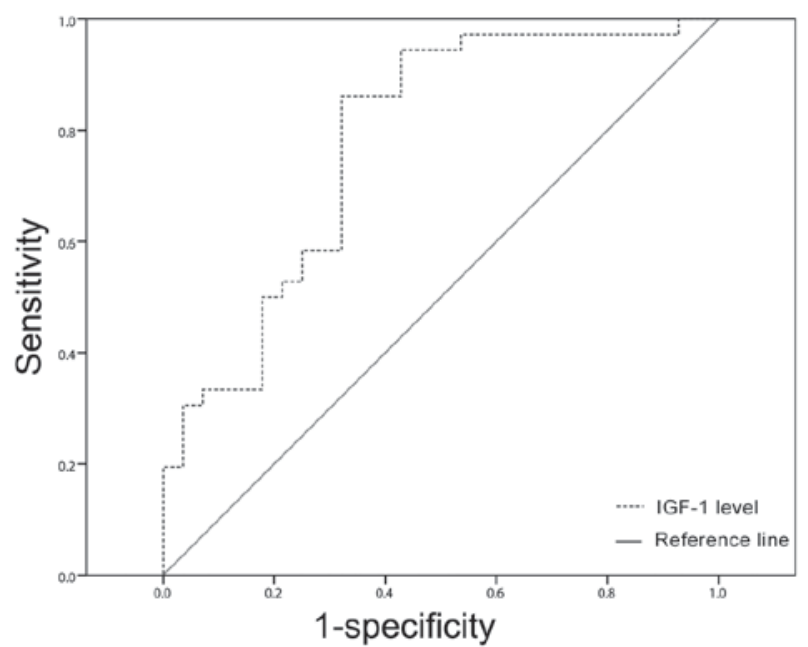

Figure 3. Receiver operating characteristic curve to predict the death of patients with sepsis according to serum IGF-1 levels. IGF-1, insulin-like growth factor.

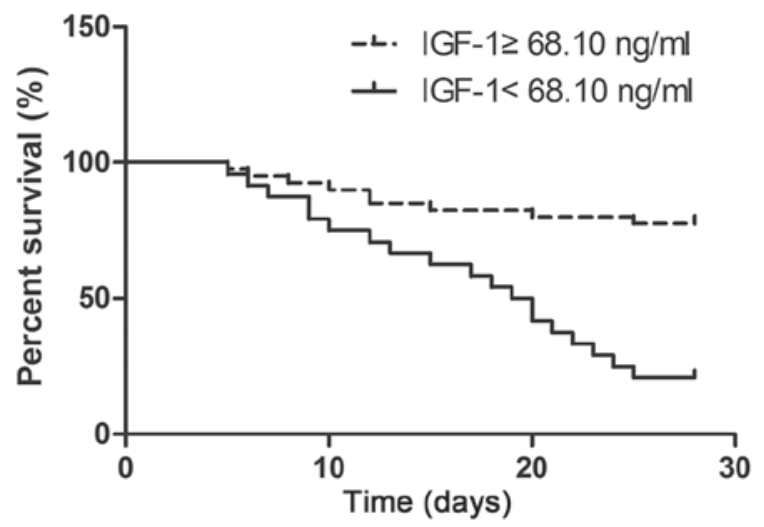

Figure 4. Patients with low serum IGF-1 levels exhibit lower 28-day survival rates, as compared with patients with high serum IGF-1 levels. IGF-1, insulin-like growth factor.

IGF-1 reduces $\mathrm{H}_{2} \mathrm{O}_{2}$-induced cell death and may be regulated by $m i R N A-1$. In a preliminary experiment, the oxidative stress induced by $\mathrm{H}_{2} \mathrm{O}_{2}$ was confirmed because increased ROS levels were detected in cells treated by $\mathrm{H}_{2} \mathrm{O}_{2}$ (data not shown). As shown in Fig. 7, $100 \mu \mathrm{M} \mathrm{H}_{2} \mathrm{O}_{2}$ caused more apoptosis in A549 cells and HKC cells; the relative DNA fragment percentage in untreated cells was $220 \pm 20$ and $260 \pm 26 \%$, respectively $(\mathrm{P}<0.05)$. However, in $30 \mathrm{ng} / \mathrm{ml}$ IGF-1-treated A549 and HKC cells, the $\mathrm{H}_{2} \mathrm{O}_{2}$ caused relative DNA fragment percentages of only $150 \pm 18$ and $130 \pm 16 \%$, respectively $(\mathrm{P}<0.05)$. This indicated that $30 \mathrm{ng} / \mathrm{ml} \mathrm{IGF-1} \mathrm{treatment} \mathrm{may} \mathrm{reduce} \mathrm{the} \mathrm{apoptosis}$ induced by $\mathrm{H}_{2} \mathrm{O}_{2}$.

As shown in Fig. 8, $100 \mu \mathrm{M} \mathrm{H}_{2} \mathrm{O}_{2}$ also induced increased expression of miRNA-1 in A549 and HKC cells, which indicated that oxidative stress may result in elevated miRNA-1 expression. Furthermore, as shown in Fig. 9, transfection of miRNA-1 mimics effectively inhibited the expression of IGF-1 mRNA in A549 cells and HKC cells; however, the transfection of negative control did not influence the level of IGF-1 miRNA in cells. Following transfection of miRNA-1 mimics, A549 cells and HKC cells exhibited increased sensitivity to exposure to $100 \mu \mathrm{M} \mathrm{H}_{2} \mathrm{O}_{2}$, manifesting as an increase in apoptosis. Transfection with negative control had no effect (Fig. 10). These results suggested that IGF-1 was able to reduce oxidative stress-induced cell death and, notably, may be regulated by miRNA-1.

\section{Discussion}

In sepsis, excessive reactive oxygen species (ROS) generated from oxidative stress is the main pathogenic mechanism for the occurrence of MODS in patients with sepsis, which is influential of the patient's disease condition and prognosis $(16,17)$ The mechanism of this process can simply described as follows: When sepsis occurs, lipopolysaccharide binding proteins on the surfaces of neutrophils and mononuclear macrophages bind with endotoxins, which activates the intracellular xanthine oxidase to release a large number of electrons and produce excess ROS, which may lead to oxidative stress status $(5,18,19)$. Excess ROS can cause damage to mitochondria and induce apoptosis, and more importantly, activate the inflammatory signaling pathways, and activate complement, resulting in a loss of control of inflammatory reactions and damage to multiple organs $(20,21)$. Therefore, the monitoring of oxidative stress-related biomarkers and anti-oxidative stress therapy may be used as a means for assessing the disease conditions and treatment of patients with sepsis.

IGF-1 has been proven to anti-oxidative stress functions $(22,23)$. Thus, IGF-1 has the potential to become a biomarker and therapeutic target of sepsis. It has been demonstrated that IGF-1 levels in critical patients typically exhibit a declining trend (24). Therefore, this study focused on the changes in IGF-1 levels in patients with sepsis. The findings demonstrated that the IGF-1 levels of patients with sepsis were significantly lower than those of healthy subjects, and continued to decline with the aggravation of the disease condition. Meanwhile, we found the IGF-1 levels of patients with sepsis who did not survive the 28-day follow-up were significantly lower than those of the patients who survived, and the patients with lower IGF-1 expression exhibited a lower survival rate. These results indicated that IGF-1 may be used to evaluate the severity of sepsis in patients and predict their prognosis. It has previously been have shown that IGF-1 is able to protect cells from injury induced by oxidative stress (25); although, on the other hand, a higher oxidative stress level in sepsis patients was also observed in a series of studies $(16,26)$. Considering these findings, we speculated that low levels of IGF-1 may not antagonize oxidative stress, thus, the patients with low IGF-1 expression may suffer from more oxidative injury when accompanied by severe disease and poorer prognosis. In vitro experiments have demonstrated that IGF-1 was able to reduce the intestinal epithelial cell injury caused by oxidative stress (25). In pluripotent stem cell experiments, researchers found that IGF-1 prevented oxidative stress-induced apoptosis (7). It is generally accepted that the mechanism of IGF-1-induced inhibition of oxidative stress injury is realized through indirect approaches, rather than directly, by reducing the products of oxidative stress. Possible mechanisms include: i) Increased expression of the antioxidants, for example, increased tetrahydrobiopterin expression; ii) increasing the expression of antioxidant enzymes, such as 

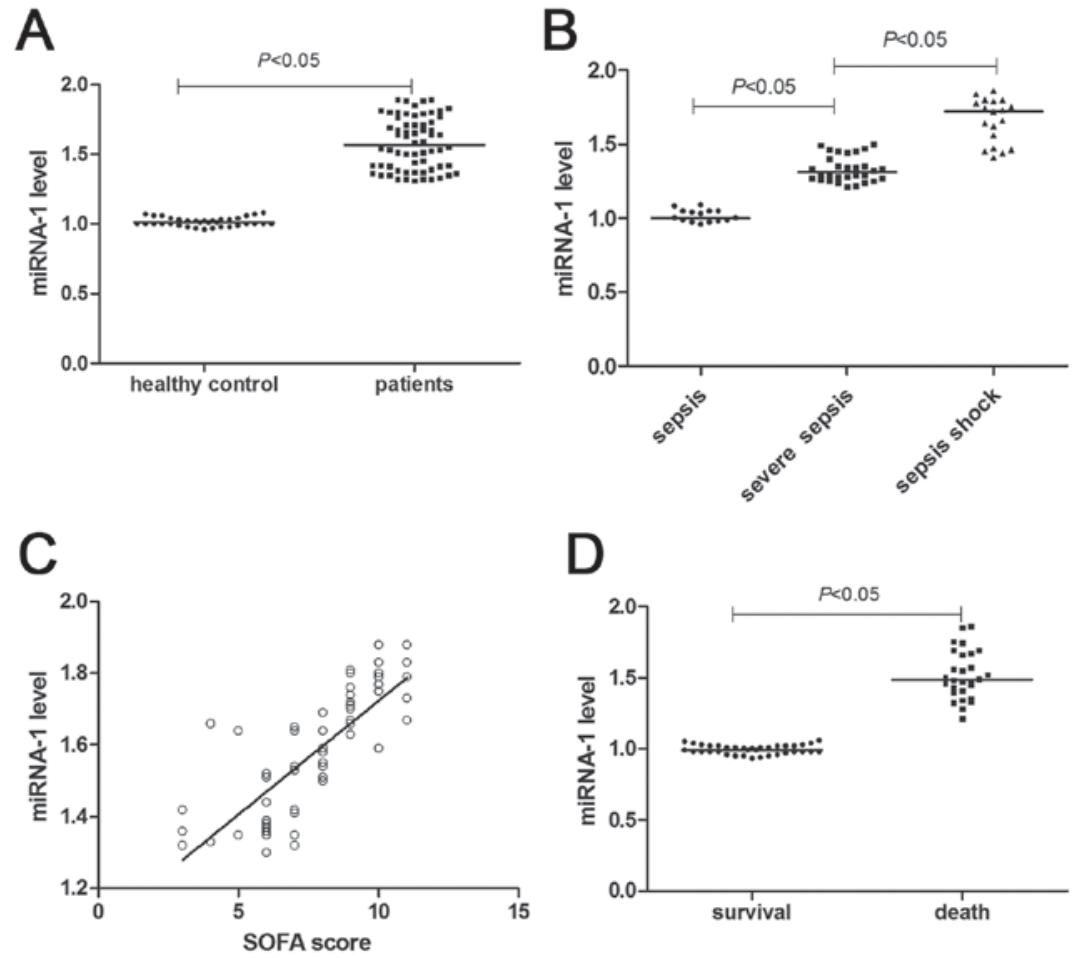

Figure 5. Serum miRNA-1 levels in patients with sepsis. (A) Serum miRNA-1 levels increased in patients with sepsis, as compared with the healthy control group. (B) Serum miRNA-1 levels were correlated with the severity of illness for patients with sepsis. (C) miRNA-1 level was proportional to SOFA score in patients with sepsis. (D) miRNA-1 levels were elevated in patients with sepsis who did not survive the 28-day follow-up period, as compared with patients who did survive. Only significant P-values are shown. miRNA, microRNA; SOFA, sepsis-related organ failure assessment.

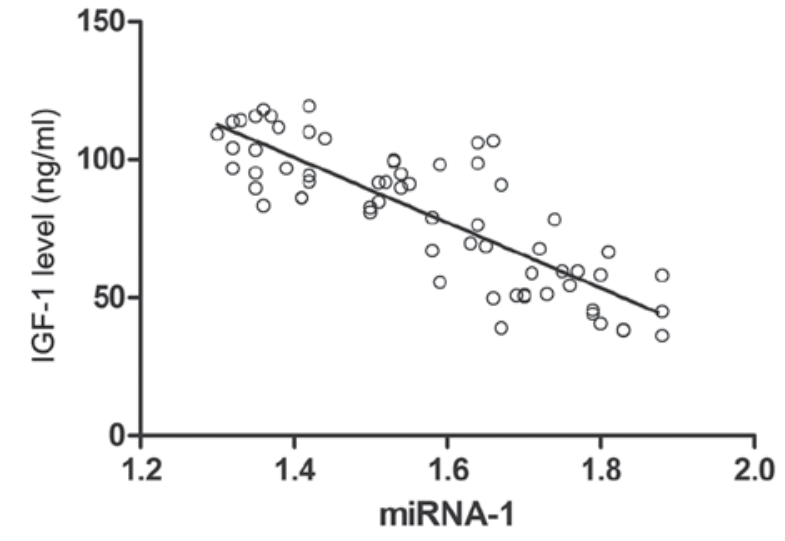

Figure 6. Serum IGF-1 levels of patients are inversely proportional to serum miRNA-1 levels. Only significant P-values are shown. IGF-1, insulin-like growth factor; miRNA, microRNA.

increased expression of glutathione peroxidase and superoxide dismutase; and iii) inhibiting the generation of inflammatory cytokines, such as reducing interleukin- 6 and tumor necrosis factor- $\alpha$ generation, thus preventing the vicious cycle of inflammation and oxidative stress $(16,22,27)$.

In order to further explore the mechanism of IGF-1 variation in patients with sepsis, miRNA-1 levels were analyzed in patients with sepsis, since IGF-1 is the target gene of miRNA-1 according to previous studies $(28,29)$. The present study demonstrated that patients with sepsis had higher plasma miRNA-1 levels, which was negatively correlated with the IGF-1.

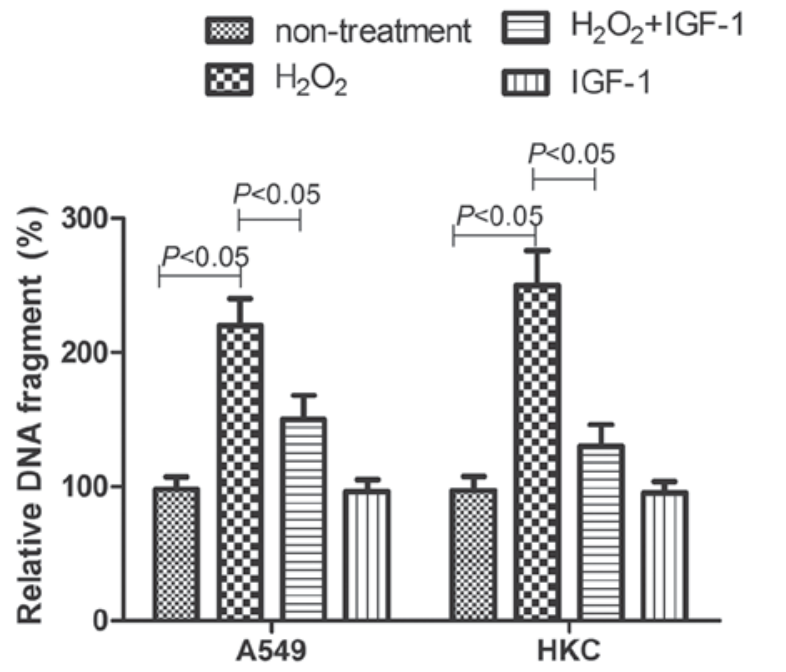

Figure 7. IGF-1 treatment reduces $\mathrm{H}_{2} \mathrm{O}_{2}$-induced cell death. Only significant $\mathrm{P}$-values are shown. IGF-1, insulin-like growth factor.

Lungs and kidneys are particularly vulnerable to injury during sepsis (30), hence we selected A549 and HKC cells to further confirm the miR-1 function in ROS induced cell damage. $\mathrm{H}_{2} \mathrm{O}_{2}$ is able to induce oxidative stress injury, as reported by various studies $(31,32)$; therefore, $\mathrm{H}_{2} \mathrm{O}_{2}$ treatment was used in the present study to simulate oxidative stress. In our preliminary experiment, $\mathrm{H}_{2} \mathrm{O}_{2}$-induced oxidative stress was confirmed via the detection of higher ROS levels in cells treated by $\mathrm{H}_{2} \mathrm{O}_{2}$. As expected, IGF-1 was able to reduce the 


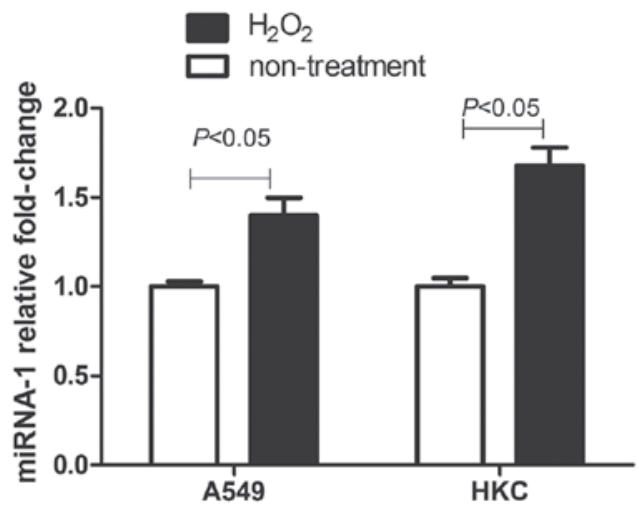

Figure $8 . \mathrm{H}_{2} \mathrm{O}_{2}$ induces higher expression of miRNA-1 in cells. miRNA, microRNA.

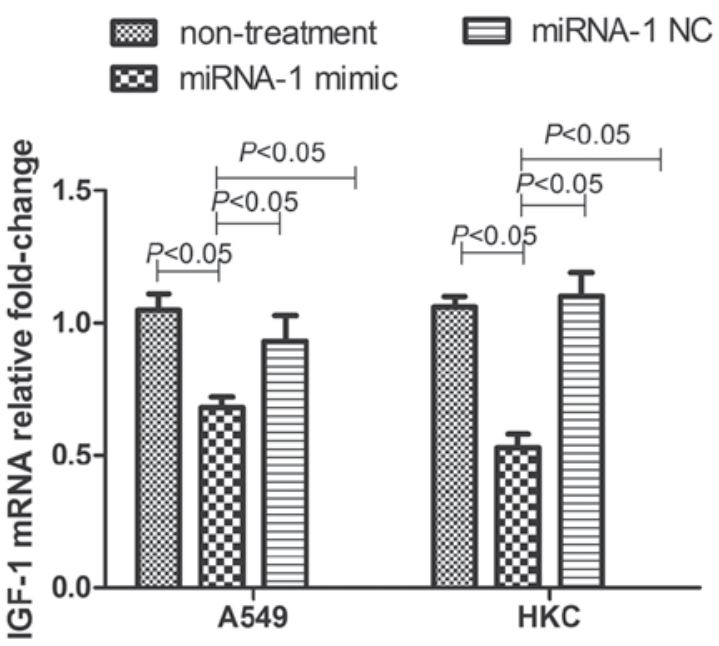

Figure 9. miRNA-1 transfection reduces the expression of IGF-1 in cells. Only significant P-values are shown. miRNA, microRNA; IGF-1, insulin-like growth factor.
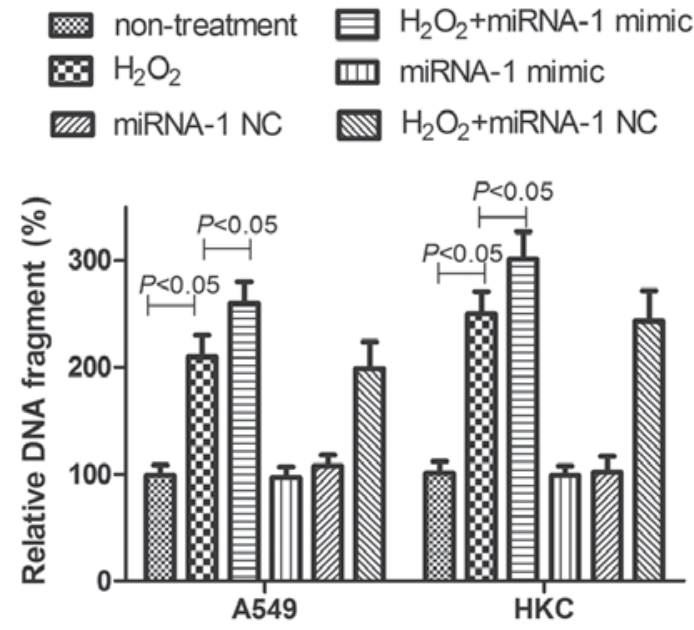

Figure 10. miRNA-1 transfection increases $\mathrm{H}_{2} \mathrm{O}_{2}$-induced cell death. Only significant $\mathrm{P}$-values are shown. miRNA, microRNA.

cell death caused by $\mathrm{H}_{2} \mathrm{O}_{2}$. Notably, miRNA-1 transfection was able to reduce the expression of IGF-1, thereby increasing $\mathrm{H}_{2} \mathrm{O}_{2}$ damage to cells. These in vitro experimental data provided more evidence that the increased expression of miRNA-1 may decrease IGF-1 levels and antagonize its anti-oxidative stress function.

In conclusion, the findings of the present study demonstrated that a lower IGF-1 level in patients with sepsis may predict more severe illness condition and poor prognosis. The possible mechanism is that the elevated miRNA-1 levels reduce IGF-1 levels, reducing the anti-oxidative stress effect of IGF-1, which increases the injury caused by oxidative stress in patients with sepsis.

\section{Acknowledgements}

This study was financially supported by a grant from Department of Health of Zhejiang Province, China (grant no. 2013RCB001).

\section{References}

1. Guerra WF, Mayfield TR, Meyers MS, Clouatre AE and Riccio JC: Early detection and treatment of patients with severe sepsis by prehospital personnel. J Emerg Med 44: 1116-1125, 2013.

2. Lekkou A, Mouzaki A, Siagris D, Ravani I and Gogos CA: Serum lipid profile, cytokine production, and clinical outcome in patients with severe sepsis. J Crit Care 29: 723-727, 2014.

3. Keegan J and Wira CR III: Early identification and management of patients with severe sepsis and septic shock in the emergency department. Emerg Med Clin North Am 32: 759-776, 2014.

4. Brosche T, Bertsch T, Sieber CC and Hoffmann U: Reduced plasmalogen concentration as a surrogate marker of oxidative stress in elderly septic patients. Arch Gerontol Geriatr 57: 66-69, 2013.

5. Karapetsa M, Pitsika M, Goutzourelas N, Stagos D, Tousia Becker A and Zakynthinos E: Oxidative status in ICU patients with septic shock. Food Chem Toxicol 61: 106-111, 2013.

6. Gu Y, Wang C and Cohen A: Effect of IGF-1 on the balance between autophagy of dysfunctional mitochondria and apoptosis. FEBS Lett 577: 357-360, 2004.

7. Li Y, Shelat $\mathrm{H}$ and Geng YJ: IGF-1 prevents oxidative stress induced-apoptosis in induced pluripotent stem cells which is mediated by microRNA-1. Biochem Biophys Res Commun 426: 615-619, 2012.

8. Essandoh K and Fan GC: Role of extracellular and intracellular microRNAs in sepsis. Biochim Biophys Acta 1842: 2155-2162, 2014.

9. Montano M: MicroRNAs: miRRORS of health and disease. Transl Res 157: 157-162, 2011.

10. Yu XY, Song YH, Geng YJ, Lin QX, Shan ZX, Lin SG and Li Y: Glucose induces apoptosis of cardiomyocytes via microRNA-1 and IGF-1. Biochem Biophys Res Commun 376: 548-552, 2008.

11. Shah G, Zielonka J, Chen F, Zhang G, Cao Y, Kalyanaraman B and See W: $\mathrm{H}_{2} \mathrm{O}_{2}$ generation by bacillus Calmette-Guérin induces the cellular oxidative stress response required for bacillus Calmette-Guérin direct effects on urothelial carcinoma biology. J Urol 192: 1238-1248, 2014.

12. Trinh MD, Ngo DH, Tran DK, Tran QT, Vo TS, Dinh MH and Ngo DN: Prevention of $\mathrm{H}_{2} \mathrm{O}_{2}$-induced oxidative stress in Chang liver cells by 4-hydroxybenzyl-chitooligomers. Carbohydr Polym 103: 502-509, 2014.

13. Levy MM, Fink MP, Marshall JC, Abraham E, Angus D, Cook D, Cohen J, Opal SM, Vincent JL and Ramsay G; SCCM/ ESICM/ACCP/ATS/SIS: 2001 SCCM/ESICM/ACCP/ATS/SIS International Sepsis Definitions Conference. Crit Care Med 31: 1250-1256, 2003.

14. Dellinger RP, Levy MM, Rhodes A, Annane D, Gerlach H, Opal SM, Sevransky JE, Sprung CL, Douglas IS, Jaeschke R, et al: Surviving sepsis campaign: International guidelines for management of severe sepsis and septic shock, 2012. Intensive Care Med 39: 165-228, 2013.

15. Livak KJ and Schmittgen TD: Analysis of relative gene expression data using real-time quantitative PCR and the 2-(Delta Delta C(T)) method. Methods 25: 402-408, 2001. 
16. Mühl D, Woth G, Drenkovics L, Varga A, Ghosh S, Csontos C, Bogár L, Wéber G and Lantos J: Comparison of oxidative stress \& leukocyte activation in patients with severe sepsis \& burn injury. Indian J Med Res 134: 69-78, 2011

17. Apostolova N, Garcia-Bou R, Hernandez-Mijares A, Herance R, Rocha M and Victor VM: Mitochondrial antioxidants alleviate oxidative and nitrosative stress in a cellular model of sepsis. Pharm Res 28: 2910-2919, 2011.

18. Santos RS, Silva PL, de Oliveira GP, Santos CL, Cruz FF, de Assis EF, de Castro-Faria-Neto HC, Capelozzi VL, Morales MM, Pelosi P, et al: Oleanolic acid improves pulmonary morphofunctional parameters in experimental sepsis by modulating oxidative and apoptotic processes. Respir Physiol Neurobiol 189: 484-490, 2013

19. Wang Z, Holthoff JH, Seely KA, Pathak E, Spencer HJ III, Gokden N and Mayeux PR: Development of oxidative stress in the peritubular capillary microenvironment mediates sepsis-induced renal microcirculatory failure and acute kidney injury. Am J Pathol 180: 505-516, 2012.

20. Whelan SP, Carchman EH, Kautza B, Nassour I, Mollen K, Escobar D, Gomez H, Rosengart MA, Shiva S and Zuckerbraun BS: Polymicrobial sepsis is associated with decreased hepatic oxidative phosphorylation and an altered metabolic profile. J Surg Res 186: 297-303, 2014.

21. Zapelini PH, Rezin GT, Cardoso MR, Ritter C, Klamt F, Moreira JCF, Streck EL and Dal-Pizzol F: Antioxidant treatment reverses mitochondrial dysfunction in a sepsis animal model. Mitochondrion 8: 211-218, 2008.

22. Fukuoka H, Iida K, Nishizawa H, Imanaka M, Takeno R, Iguchi G Takahashi M, Okimura Y, Kaji H, Chihara K and Takahashi Y: IGF-I stimulates reactive oxygen species (ROS) production and inhibits insulin-dependent glucose uptake via ROS in 3T3-L1 adipocytes. Growth Horm IGF Res 20: 212-219, 2010.

23. Papaconstantinou J: Insulin/IGF-1 and ROS signaling pathway cross-talk in aging and longevity determination. Mol Cell Endocrinol 299: 89-100, 2009.
24. Elijah IE, Branski LK, Finnerty CC and Herndon DN: The GH/IGF-1 system in critical illness. Best Pract Res Clin Endocrinol Metab 25: 759-767, 2011.

25. Baregamian N, Song J, Jeschke MG, Evers BM and Chung DH: IGF-1 protects intestinal epithelial cells from oxidative stress-induced apoptosis. J Surg Res 136: 31-37, 2006.

26. von Dessauer B, Bongain J, Molina V, Quilodrán J, Castillo R and Rodrigo R: Oxidative stress as a novel target in pediatric sepsis management. J Crit Care 26: 103.e1-e7, 2011.

27. Bayram F, Bitgen N, Donmez-Altuntas H, Cakir I, Hamurcu Z, Sahin F, Simsek Y and Baskol G: Increased genome instability and oxidative DNA damage and their association with IGF-1 levels in patients with active acromegaly. Growth Horm IGF Res 24: 29-34, 2014.

28. Naeem A, Zhong K, Moisá SJ, Drackley JK, Moyes KM and Loor JJ: Bioinformatics analysis of microRNA and putative target genes in bovine mammary tissue infected with Streptococcus uberis1. J Dairy Sci 95: 6397-6408, 2012.

29. Huat TJ, Khan AA, Abdullah JM, Idris FM and Jaafar H: MicroRNA expression profile of bone marrow mesenchymal stem cell-derived neural progenitor by microarray under the influence of EGF, bFGF and IGF-1. Genom Data 5: 201-205, 2015.

30. Griffiths B and Anderson ID: Sepsis, SIRS and MODS. Surgery (Oxford) 27: 446-449, 2009.

31. García-Nebot MJ, Cilla A, Alegría A and Barberá R: Caseinophosphopeptides exert partial and site-specific cytoprotection against $\mathrm{H}_{2} \mathrm{O}_{2}$-induced oxidative stress in Caco-2 cells. Food Chem 129: 1495-1503, 2011.

32. Zhai L, Zhang P, Sun RY, Liu XY, Liu WG and Guo XL: Cytoprotective effects of CSTMP, a novel stilbene derivative, against $\mathrm{H}_{2} \mathrm{O}_{2}$-induced oxidative stress in human endothelial cells. Pharmacol Rep 63: 1469-1480, 2011. 